\title{
Malignancies Associated with Extraovarian Endometriosis: A Literature Review
}

\author{
Naoki Inoue ${ }^{1}$, Takashi Hirakawa ${ }^{1}$, Junji Mitsushita ${ }^{2}$, Yoshikazu Kitahara ${ }^{1}$ and Akira Iwase ${ }^{1, *(D)}$ \\ 1 Department of Obstetrics and Gynecology, Gunma University Graduate School of Medicine, 3-39-15, \\ Showa-machi, Maebashi 371-8511, Gunma, Japan; naokiinoue1987@gmail.com (N.I.); \\ thira@gunma-u.ac.jp (T.H.); kitahara@gunma-u.ac.jp (Y.K.) \\ 2 Department of Obstetrics and Gynecology, Japanese Red Cross Maebashi Hospital, 389-1, Asakura-machi, \\ Maebashi 371-0811, Gunma, Japan; mitsushita@obgyn.jp \\ * Correspondence: akiwase@gunma-u.ac.jp; Tel.: +81-2-7220-8427
}

Citation: Inoue, N.; Hirakawa, T.; Mitsushita, J.; Kitahara, Y.; Iwase, A. Malignancies Associated with Extraovarian Endometriosis: A Literature Review. Endocrines 2021, 2, 251-265. https://doi.org/10.3390/ endocrines2030024

Academic Editor: Udo Jeschke

Received: 30 June 2021

Accepted: 6 August 2021

Published: 11 August 2021

Publisher's Note: MDPI stays neutral with regard to jurisdictional claims in published maps and institutional affiliations.

Copyright: (c) 2021 by the authors. Licensee MDPI, Basel, Switzerland. This article is an open access article distributed under the terms and conditions of the Creative Commons Attribution (CC BY) license (https:// creativecommons.org/licenses/by/ $4.0 /)$.
Abstract: Endometriosis-associated ovarian malignancies have been well documented. Although these malignancies also occur as extraovarian lesions, little is known about them. Thus, this literature review aimed to further explore these rarely experienced tumors. A total of 257 published cases between April 1990 and April 2020 were found using PubMed, and 212 cases were included in the analysis considering Sampson's criteria and the history of endometriosis. We classified these cases as follows: intestine, abdominal scar, vagina and vulva, peritoneum and deep endometriosis, urinary tract, uterine cervix, and others. Age of patients, history of endometriosis, types of past hormonal therapy, symptoms, histological types, and treatment were identified. The most common tumor site was the intestine. Endometrioid carcinoma was the dominant histological type. Contrary to the ovary, clear cell carcinoma was rare in extraovarian sites. On the other hand, clear cell carcinoma represented the largest number of abdominal scars. This difference may help us to understand the development of endometriosis-related malignancies. Hormonal treatment was mentioned in 67 cases and estrogen replacement therapy in 33 cases. Although risks of estrogen therapy are still controversial, the highly differentiated histological types and hormone-dependent characteristics of endometriosis-associated malignancy should be considered. Physicians should be careful about estrogen monotherapy after hysterectomy and long-term hormone replacement therapy in patients with a history of endometriosis.

Keywords: clear cell carcinoma; extraovarian endometriosis; endometrioid carcinoma; hormone replacement therapy; infertility; pelvic pain; perimenopause; sarcoma; serous membrane; uterine cervical neoplasms

\section{Introduction}

Endometriosis is defined as the presence of endometrial lesions outside the uterine corpus, affecting $6-10 \%$ of women of reproductive age [1]. Endometriosis in the ovary, uterine serosa, cul-de-sac, and uterine ligament is often experienced. Irving and Clement classified endometriosis into three categories: common site, less common site, and rare site [2]. Less and rare sites might variously include the intestine, skin, urinary tract, uterine cervix, and vagina. In 2021, the international working group of the American Association of Gynecologic Laparoscopists, the American Society for Reproductive Medicine, the European Society for Gynaecological Endoscopy, the European Society of Human Reproduction and Embryology, and the World Endometriosis Society proposed a draft classification for endometriosis based on disease subtypes and locations. The common issues in endometriosis are infertility and chronic pelvic pain. The prevalence of endometriosis is $21-50 \%$ in infertile women and $82 \%$ in women who have chronic pelvic pain [3,4]. Malignant transformation is the most serious problem in perimenopausal women. 
In 1925, Sampson et al. defined endometriosis-associated cancer as (i) evidence of endometriosis close to the tumor, (ii) exclusion of invasion from other sources, and (iii) presence of tissue resembling endometrial stroma surrounding characteristic epithelial glands [5]. Scott et al. added another definition, (iv) histological evidence of transition from benign changes that characterize endometriosis to malignant changes of cancer (transitional zone) [6]. However, the transitional zone is seen in only $36-42 \%$ cases and is optional [7].

Malignant transformation of ovarian endometriosis has been well documented. Kobayashi et al. conducted a prospective cohort study of 6398 cases of ovarian endometriosis, which resulted in 46 cases $(0.72 \%)$ being diagnosed with ovarian carcinoma [8]. In population-based studies, the incidence of ovarian cancer in patients with a history of ovarian endometriosis is 1.35-1.49 times greater compared with those without this history $[9,10]$. The common histological types were clear cell carcinoma (70\%) and endometrioid carcinoma (24\%) [11]. Pearce et al. summarized 13 case-control studies and reported the highest odds ratio of 3.05 for clear cell carcinoma, followed by LG-serous (2.11) and endometrioid carcinoma (2.04) in patients with endometriosis [9]. There are two hypotheses about links between endometriosis and ovarian cancer. One is due to common risk factors, and the other is that endometriosis may lead to carcinogenesis. Infertility and delayed menopause increase the risk, while hysterectomy, use of oral contraceptives, and tubal ligation decrease the risk and are common risk factors [12]. On the other hand, the ability of endometriosis to become malignant has already been reported in many papers. One of the reasons is that 14.7 to $22.8 \%$ of ovarian carcinomas coexist with atypical endometriosis $[13,14]$. Therefore, it is possible that endometriosis may become cancerous through atypical endometriosis, although its existence as an intermediate precursor has not been confirmed. Recently, the detection of PTEN, PIK3CA, and ARID1A mutations in benign or atypical endometriotic lesions [15-17], which have been also reported in ovarian clear cell carcinoma and endometrioid carcinoma, supports the possibility of malignant transformation of endometriosis.

On the other hand, neoplasms arising in extraovarian endometriosis are less known than those in ovarian endometriosis. Approximately $20 \%$ of cases of endometriosis occur as extraovarian endometriosis $[18,19]$. Mandai et al. reported a nationwide study of cancer in patients with less common/rare site endometriosis. The coexistence rate of malignancy was $0.79 \%$ and was more rare compared to in the ovary [20]. In addition, they noted that the histologic type of the tumor might differ according to the site of origin [20]. The most common site was the intestine and the most common histological type was endometrioid carcinoma, which was different from those of ovarian origins. Moreover, various histological types of malignancy have been reported regarding extraovarian endometriosis: endometrioid stromal sarcoma, adenosarcoma, and carcinosarcoma [21].

Several case series on malignant transformation of extraovarian endometriosis were limited to certain organs, such as the intestine and skin [22,23]. Here, we conduct a literature review of these rarely experienced tumors. This attempt may assist in improving our understanding of endometriosis-associated extraovarian malignancies.

\section{Material and Methods}

We searched publications and conference abstracts from April 1990 to April 2020 using PubMed using the following search terms (keywords): ("endometriosis" OR "extraovarian endometriosis") AND (bladder OR ureter OR "urinary tract" OR diaphragm OR lung OR pleura OR thoracic OR die OR "deep endometriosis" OR peritoneum OR intestine OR bowel OR colon OR rectum OR sigmoid OR rectosigmoid OR skin OR scar OR umbilical OR "uterine cervix" OR vagina OR vulva) AND (cancer OR carcinoma OR sarcoma OR "malignant transformation"). We also manually searched reference lists of all original case reports and case series to identify other eligible cases. A.I. performed the search for the reports. N.I. mainly checked the reports.

Inclusion and exclusion of cases were discussed by the authors until a consensus was reached. Regarding each case, those with coexistence of endometriosis (Sampson criteria) 
or those with a history of endometriosis were confirmed, and those with histological type consistent with endometriosis-related malignancies were included. All cases were classified according to localization: intestinal abdominal scar; vagina and vulva; peritoneum and deep endometriosis; urinary tract; uterine cervix; or others. We identified age of patients, history of endometriosis, types of past hormonal therapy, symptoms, histology, and treatment.

\section{Results}

A total of 158 reports were identified, including 19 case series and 147 case reports. Out of the identified 258 cases, 45 cases were excluded as follows: detail was not described about each cases (15 cases in 1 case series) [24]; benign diseases (11 cases: 8 cases including 2 case series, mesothelial tumor [25-29]; 1 case, abscess [30]; 1 case, adenofibroma [31]; 1 case, endosalpingiosis was suspected by histological image [32]); no history or coexistence of endometriosis (7 cases) [33-39]; histological types that were not associated with endometriosis ( 3 cases) [40-42]; coexisting intestinal cancer ( 2 cases) [43,44]; dissemination of ovarian tumor ( 2 cases) [45,46]; tumor derived from adenomyosis ( 2 cases) [47]; primary peritoneal borderline tumor (1 case) [48]; malignancy from endosalpingiosis (1 case) [42]; review from other papers (1 case) [49].

Finally, 213 cases (16 case series and 127 case reports) were included and classified as the intestine (73 cases); abdominal scar (44 cases); vagina and vulva (33 cases); peritoneum and deep endometriosis (30 cases); urinary tract (17 cases); uterine cervix (4 cases); and other sites (12 cases). All cases and studies are shown in the Supplementary Materials (Figure S1) and correspondence of the site classification with the draft classification of the international working group is noted in Table 1.

Table 1. Correspondence table of tumor site, from this review to newly proposed diagnosis by the international working group of AAGL, ASRM, ESGE, ESHRE and WES.

\begin{tabular}{cc} 
This review & International working group of AAGL, ASRM, ESGE, ESHRE and WES \\
Intestine & Bowel \\
Abdominal scar & Ectopic growth of endometrial-like tissue outside the abdominal cavity \\
Vagina and vulva & Extra-abdominal endometriosis, Iatrogenic endometriosis \\
Peritoneum and & Paravesical space, Pouch of Douglas, Paravesical space, Prevesical space, \\
deep endometriosis & Retrocervical space, Retropubic space, Uterosacral ligaments \\
Urinary tract & Bladder, Paravesical space, Pararectal space \\
Uterine cervix & Ectopic growth of endometrial-like tissue outside the abdominal cavity \\
Others & Ectopic growth of endometrial-like tissue outside the abdominal cavity \\
\hline
\end{tabular}

AAGL, the American Association of Gynecologic Laparoscopists; ASRM, the American Society for Reproductive Medicine; ESGE, the European Society for Gynaecological Endoscopy; ESHRE, the European Society of Human Reproduction and Embryology; WES, and the World Endometriosis Society.

\subsection{Overall Patient Characteristics}

The mean age of patients at the time of diagnosis was $51.9 \pm 11.0$ years (mean \pm standard deviation [SD]). The number of patients with a history of endometriosis was 81 (38.0\%). Out of 119 patients where hormonal treatment was mentioned, 68 had received hormonal therapy and 33 had undergone estrogen replacement therapy (Table 2). The most common histological types were endometrioid carcinoma (EC) in 80 cases, followed by clear cell carcinoma (CCC) in 56 cases, endometrioid stromal sarcoma (ESS) in 27 cases, adenosarcoma (AS) in 14, mixed epithelial carcinoma (MEC) in 10 cases, low malignant potential epithelial tumor (LMP) in 7 cases, other carcinomas (Others) in 7 cases (serous carcinoma, 5; mucinous carcinoma, 1; not detailed described, 1), carcinosarcoma (CS) in 6 cases, and peritoneal malignant mesothelioma (PMM) in 6 cases (Table 3$)$. 
Table 2. Hormonal therapy in each extraovarian site.

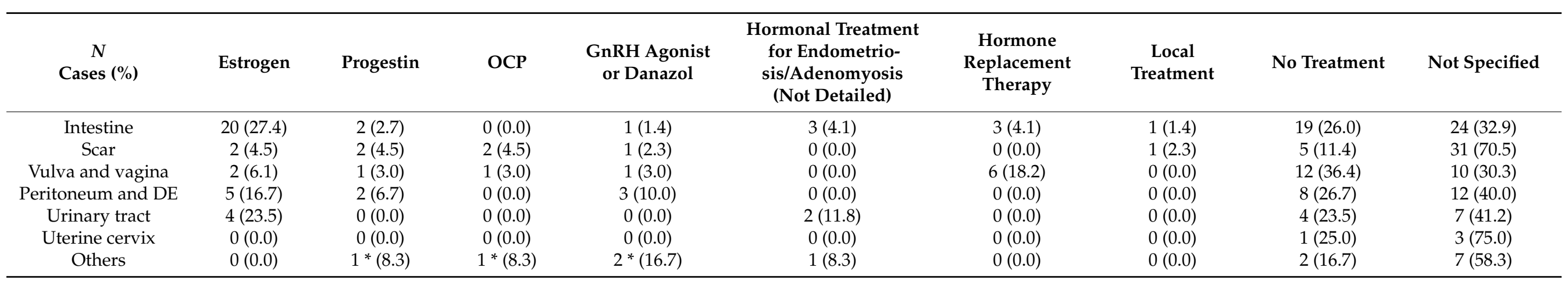

$\mathrm{DE}$, deep endometriosis; OCP, oral contraceptive pills; GnRH, gonadotropin-releasing hormone. * One case used progestin and GnRH agonist. Another 1 case used OCP and GnRH agonist.

Table 3. Histological classification in each extraovarian site.

\begin{tabular}{|c|c|c|c|c|c|c|c|c|}
\hline $\begin{array}{c}N \\
\text { Cases (\%) }\end{array}$ & EC & CCC & MEC & Other Carcinomas & LMP & Carcinosarcoma & AS and ESS & MM \\
\hline Intestine & $36(49.3)$ & $3(4.1)$ & $4(5.5)$ & $2(2.7)$ & $6(8.2)$ & $4(5.5)$ & $18(24.7)$ & $0(0.0)$ \\
\hline Abdominal scar & 7 (15.9) & $28(63.6)$ & $4(9.1)$ & $3(6.8)$ & $0(0.0)$ & $1(2.3)$ & $1(2.3)$ & $0(0.0)$ \\
\hline peritoneum and DE & $10(33.3)$ & $3(10.0)$ & $1(3.3)$ & $0(0.0)$ & $1(3.3)$ & $1(3.3)$ & $8(26.7)$ & $6(20.0)$ \\
\hline Urinary tract & $6(35.3)$ & $6(35.3)$ & $1(5.9)$ & $1(5.9)$ & $0(0.0)$ & $0(0.0)$ & $3(17.6)$ & $0(0.0)$ \\
\hline Uterine cervix & $1(25.0)$ & $2(50.0)$ & $0(0.0)$ & $0(0.0)$ & $0(0.0)$ & $0(0.0)$ & $1(25.0)$ & $0(0.0)$ \\
\hline Others & $3(25.0)$ & $5(41.7)$ & $0(0.0)$ & $0(0.0)$ & $0(0.0)$ & $0(0.0)$ & $4(33.3)$ & $0(0.0)$ \\
\hline
\end{tabular}

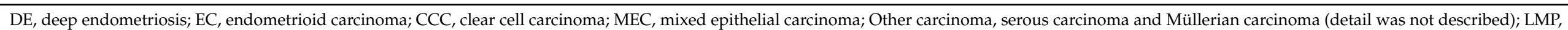
low malignant potential epithelial tumor; AS and ESS, adenosarcoma and endometrioid stromal sarcoma; MM, malignant mesothelioma. 


\subsection{Intestine}

The number of cases classified in the intestine was 73, which was the most common. The mean age was $55.3 \pm 12.4$ years (mean $\pm \mathrm{SD}$ ). Twenty-eight patients had a history of endometriosis. Twenty patients had a history of estrogen replacement therapy. In these cases, 16 patients received estrogen replacement therapy. The following symptoms were found: abdominal pain in 27 cases, rectal bleeding or melena in 24 cases, abdominal mass in 16 cases, obstruction in 8 cases, and constipation in 5 cases. The most common histological types were EC in 36 cases followed by ESS in 12 cases, AS and LMP in 6 cases, CS and MEC in 4 cases, CCC in 3 cases, and others (serous carcinoma) in 2 cases. Surgical treatment was performed in 71 cases. Chemotherapy was administered in 19 patients and radiation therapy in 11 cases.

\subsection{Abdominal Scar}

Forty-four cases were classified as abdominal scars. The scar sites included cesarean section (37 cases), laparoscopic surgery ( 2 cases), abdominal hysterectomy (1 case), and other open surgeries of the uterus and adnexa (4 cases). The mean age was $46.2 \pm 7.6$ years (mean \pm SD). Only nine patients had a history of endometriosis. Estrogen replacement therapy was administered in two cases.

Most patients (40 cases) complained of mass on the scars. Only eight patients complained of pain. The most common histological type was CCC in 28 cases, followed by EC in 7 cases, MEC in 4 cases, and others in 3 cases ( 2 serous carcinoma and 1 Müllerian carcinoma). CS and ESS were seen in one case each. Surgical treatment was performed in 41 cases. Chemotherapy was administered in 29 patients and radiation therapy in 14 cases.

\subsection{Vagina and Vulva}

A total of 33 cases were classified as vagina and vulva; 25 cases were classified as vagina and 8 cases were classified as vulva. A total of 18 cases classified as vagina had a history of hysterectomy, and 5 cases classified as vulva had lesions in the episiotomy site. The average age was $53.0 \pm 10.5$ years (mean $\pm \mathrm{SD}$ ). A history of endometriosis was found in 18 patients. A history of estrogen replacement therapy was observed in nine cases and unopposed estrogen therapy was specified in only two cases. Only one patient received progestin. The most common symptom was genital bleeding in 15 cases, followed by masses in 8 cases, and pain in 3 cases. Cases of vaginal discharge, urinary incontinence, genital ulcer, and by chance during regular examinations were found in one case each. The most common histological type was EC in 17 cases, followed by CCC in 9 cases, ESS in 4 cases, AS in 2 cases, and others (serous carcinoma) in 1 case. Six out of these nine CCC cases were in the vulva. Surgical treatment was performed in 30 cases. Chemotherapy was administered in 11 patients and radiation therapy in 12 patients.

\subsection{Peritoneum and Deep Endometriosis}

Thirty-one cases were classified as peritoneal or deep endometriosis. A total of 13 cases had lesions in the pelvic peritoneum, followed by 12 in cul-de-sac and rectovaginal septum, and 4 cases in retroperitoneum. Because of the close proximity of the cervix, upper vagina, and rectum, lesions originating from cul-de-sac or rectovaginal septum can easily invade these organs, and cases with completely separate lesions are rather rare. Therefore, we classify the cases in which the primary tumor is clearly located in rectovaginal septum or retroperitoneal other than specific organs. The mean age was $51.0 \pm 11.1$ years (mean \pm SD). Sixteen patients had a history of endometriosis. Estrogen replacement therapy was administered in five cases. The most common symptom was pain in seven cases, followed by masses in five cases and genital bleeding in three cases. Constipation, abdominal discomfort, abdominal bloating, pollakiuria, weight loss, dysmenorrhea, or urethral obstruction, and incidental detection was observed in one case each. The most common histological type was EC in 10 cases followed by PMM in 6 cases, ESS in 5 cases, CCC and AS in 3 cases, and CS, LMP, and MEC in 1 case. Surgical treatments were 
performed in all 28 cases described, chemotherapy was administered in 8 cases, and radiotherapy in 4 cases.

\subsection{Urinary Tract}

In 17 cases classified as urinary tract lesions, 10 cases were bladder and 6 were ureter lesions. The median age was $51.1 \pm 8.4$ years (mean \pm SD). Five patients had a history of endometriosis. In five cases of hormonal therapy, four underwent estrogen replacement therapy. The most common symptom was hematuria in seven cases, followed by pain in seven cases (two cases overlapping with hematuria). Urinary incontinence, bladder irritation, and difficulty urinating were observed in one patient each. In cases of bladder malignancies, one patient experienced vaginal bleeding, three cases were asymptomatic, and one case had abdominal tension. The most common histological type was EC and CCC in six cases, followed by AS in two cases, and ESS, MEC and others (mucinous carcinoma) in one case. Surgical treatments were performed in all 17 patients. Chemotherapy was administered in 12 cases and radiotherapy in 1 case.

\subsection{Uterine Cervix}

Four cases were classified as having uterine cervix lesions. The median age was $51.3 \pm 6.3$ years $($ mean $\pm \mathrm{SD}$ ). No patient had a history of endometriosis or had undergone hormonal therapy. Vaginal bleeding was seen in two cases, followed by vaginal discharge in one case, and dysmenorrhea in one case. Regarding histological type, CCC was seen in two cases, followed by EC and ESS in one case. Surgical treatment was performed in all four patients. Chemotherapy was administered in one patient and radiation therapy in one patient.

\subsection{Others}

Twelve cases were identified as having malignancies in other organs. Malignancies in the diaphragm, inguina, liver, omentum, and umbilicus were confirmed in two cases, and lesions in the chest wall and sciatic nerve were seen in one case each. The mean age was $52.9 \pm 10.3$ years (mean $\pm \mathrm{SD}$ ). Five patients had a history of endometriosis. No estrogen replacement therapy was administered. Symptoms varied depending on the site, including: pain (chest wall, one case; inguinal, one; liver, one), mass (inguinal, one; umbilicus, two), general checkup (diaphragm, two), abdominal distention or discomfort (omentum, two), left lower limb motor nerve palsy (sciatic nerve, one), and no detailed description (liver, one). The most common histological type was CCC in five cases (inguinal, two; diaphragm, one; liver, one; umbilicus, one), EC in three cases (chest wall, one; diaphragm, one; umbilicus, one), ESS in three cases (liver, one; omentum, one; sciatic nerve, one), and AS in one case (omentum, one). Surgical treatment was performed in all 12 patients. Chemotherapy was administered in six cases and radiation therapy in three cases.

\section{Discussion}

\subsection{Intestine}

In this review, most reports described intestinal lesions. Mandai et al. reported 11 cases of malignancy from rare/less site endometriosis and described that the most common site was the intestine and included 7 cases [20]. In addition, they noted that the rate of coexistence of malignant lesions in intestinal endometriosis was $1.2 \%$ ( $7 / 607$ cases) [20]. In this review, 56 cases $(76.7 \%)$ of malignancies occurred in the rectosigmoid colon, which is consistent with previously reported data that most intestinal endometriosis occurs in the rectosigmoid colon [50].

In the present report, many patients exhibited abdominal pain, rectal bleeding, or abdominal mass. Slavin et al. reported 23 cases of endometriosis-associated intestinal tumors (EAITs) and noted the most common symptoms were abdominal pain, bloody stools, and abdominal mass [22]. Although these symptoms resemble those of colorectal cancer, they described that patients had a history of endometriosis with long-time cyclic 
intestinal symptoms [22]. They also reported that the mean age was 30-50 years old, which was younger than in those with typical colorectal cancer [22]. On the other hand, the mean age was not so young in this literature (55.3 years old). In addition, one-fourth of patients with malignancy in intestinal endometriosis had a history of pelvic endometriosis [51]. In this review, the result indicating that $38.4 \%(28 / 73)$ of cases had a history of endometriosis was similar to this previous report. However, since $61.6 \%$ of patients did not describe endometriosis, it should be considered as a differential diagnosis if they are relatively young, even if they have no history of endometriosis.

Differentiating intestinal endometriosis-associated cancer in inflammatory bowel disease may sometimes be difficult, and patients can be initially treated with steroids $[52,53]$. Gatas et al. first reported a case of ulcerative colitis. Nine months later, a CT scan revealed a rectal mass, so an intestinal resection for obstruction was performed, and pathological diagnosis revealed endometrioid carcinoma [52]. Molberg et al. described a case initially seen as Crohn's disease and a diagnosed tumor causing intestinal obstruction as an abscess [53]. Since drainage did not improve this patient's condition, they performed a right hemicolectomy and finally diagnosed the patient with EC of the intestine [53]. Both patients had a history of surgery due to endometriosis [52,53]. If a patient with suspected inflammatory bowel disease has a history of endometriosis, it is necessary to consider possibilities of exacerbation of endometriosis and endometriosis-related malignant tumors.

EC was the most common and CCC was less common in this review. This is in contrast to ovarian endometriosis, in which most malignancies occur as CCC (70\%) [9]. Mandai et al. also explained this tendency based on the tissue microenvironment [20]. They indicated that there were few cystic lesions in deep endometriosis, while most cases of ovarian endometriosis had iron-rich cystic fluid causing oxidative stress.

Regarding pathological diagnosis, it is helpful when the tumor extends outside the gastrointestinal wall. Some reports have shown that histological examination of preoperative biopsy tissue can be negative $[54,55]$, which might be due to extramural extension. In addition, several studies have stated that it is important to consider occurrence of endometriosis. In this study, 64 out of 73 cases of intestinal lesions had coexistence of endometriosis. Immunohistochemical stains for cytokeratin7 / 20 and PAX8 are useful to distinguish EC from colorectal cancer [56].

ESS is a malignant mesenchymal neoplasm resembling proliferative-type endometrial stroma outside the uterus and was found in 15\% (12 cases) of intestinal cases in this literature review. In the uterus, the same histological type is called endometrial stromal sarcoma and accounts for $0.2 \%$ of all gynecologic malignancies. Although the etiology of ESS is unknown, Masand et al. reported 63 cases of ovarian endometrioid stromal sarcoma and confirmed the coexistence of endometriosis in $60 \%$ of these cases [57], indicating the possibility of endometriosis as the origin of ESS. For distinguishing ESS from gastrointestinal stromal tumors (GISTs), immunohistochemical stains for estrogen receptor, progesterone receptor, and CD117 (c-kit) are helpful [58-60].

\subsection{Abdominal Scar}

Most of these tumors occurred in a cesarean section scar (37/44 cases). In the remaining seven cases, two cases had lesions in laparoscopic surgical sites [61,62]. In six cases, three cases had surgical history of endometriosis [62,63], one case of myomectomy [64], and one case of uterine perforation [65]. These results indicate that various surgeries that expose endometriotic tissues or endometrial tissues increase risks of malignancy arising in scar endometriosis. The incidence of scar endometriosis has been reported to be $0.03-0.45 \%$ after cesarean section $[64,66]$. It has been reported that $14-26 \%$ of abdominal scar endometriosis is associated with pelvic endometriosis [67].

Time from cesarean section to scar endometriosis was reported to be 7-35 months [67]. Considering the mean age of cases of cesarean scar in this study (46.2 years old), it is suggested that the period from cesarean section to carcinogenesis is approximately 10-20 years. Bats et al. and Shalin et al. listed differential diseases such as abscesses, hematomas, 
desmoids, sarcomas, metastatic diseases, pyogenic granulomas, and melanomas [68,69]. For tumors formed in wounds of patients with a history of surgery, it is necessary to consider wound endometriosis and endometriosis-related malignant tumors.

Tumors on abdominal scars are easy to approach for biopsy, which was effective in establishing diagnosis in some cases [70-75]. However, Matsuo et al. experienced a case where a malignant lesion could not be detected at the time of biopsy $[63,65]$. Thus, surgery should be performed if malignancy is suspected based on physical or imaging findings.

Of note, CCC was the most common histological type at this site, while intestinal cases included a small number of CCC cases. Although the cases of episiotomy scar were classified as vulva, cases of episiotomy scars also showed CCC dominance ( $4 / 5$ cases). As mentioned in the intestine, it may be possible that some type of differences in the microenvironment of the scar or abdominal wall might have influenced this tendency. On the other hand, most of the cases of abdominal scar had experienced a cesarean scar lesion (37 cases), and only six cases had a history of endometriosis. Therefore, it may be possible that endometrial tissues affected by pregnancy are associated with this difference in histological type. These results may help us understand the development of endometriosis-related malignancies.

\subsection{Vagina and Vulva}

The incidence of vaginal endometriosis is rare, accounting for approximately $2 \%$ of all endometriosis cases, and the incidence of vaginal malignancies derived from endometriosis is expected to be extremely low [76]. Shah et al. demonstrated that the proportion of endometriosis-associated malignancy in vaginal tumors was 3.6-11.1\% [77]. Staats et al. reported a case series of endometrioid carcinoma with vaginal endometriosis, and 3 out of 18 cases had a history of total hysterectomy without a history of endometriosis [23]. Although Staats et al. showed that carcinogenesis could be a consequence of endometriosis, they also mentioned that hysterectomy itself contributed to carcinogenesis through development of endometriosis [23]. In this review, the existence of five cases with a history of hysterectomy without a history of endometriosis may support this idea $[19,21,23]$.

On the other hand, 14 cases of vaginal lesions had a history of endometriosis. Furthermore, 18 cases had a history of hysterectomy. This suggests the possibility that severe deep endometriosis was present in the background in these cases. The result that endometrioid carcinoma accounted for $71 \%(17 / 24)$ of this lesion was similar to that in the intestine. This implies a hypothesis indicating that the presence of severe pelvic endometriosis requiring hysterectomy rather than surgery itself represents a major risk factor.

Five out of eight cases of vulva lesions occurred in an episiotomy scar, and four of them had clear cell carcinomas. This tendency is similar to that observed in abdominal scar lesions. Three cases of this site did not have a history of episiotomy. Regarding the pathophysiology of this lesion, other than lymphatic or hematogenous transfer, the hypothesis that endometriotic tissues spread via the Nuck duct has been described [78].

\subsection{Peritoneum and Deep Endometriosis}

Infiltration in neighboring organs, such as the intestine, vaginal wall, or urinary tract, causes various symptoms in patients after hysterectomy. Therefore, there were cases that could not be easily distinguished from intestinal or bladder cases [42,79]. Most of the tumors in this category were located in the pelvis and close to the ovaries. Shigeta et al. described a case where the tumor was difficult to distinguish from an ovarian tumor preoperatively [80]. However, Johnson et al. reported a case of peritoneal clear cell carcinoma with a multicystic and multiseptated appearance and heterogeneous solid parts, which is different from typical ovarian CCC [81].

This was similar to the intestinal and urinary tract lesions in which many EC cases were included. Out of the five ESS cases, two cases were high-grade ESS who died of disease (6 months [82] and 24 months [21]). Poor prognosis of high-grade ESS is similar to that of the uterus. 
Butnor et al. described six cases of PMM with peritoneal and/or adnexal endometriosis [83]. Although most of the malignant mesothelioma are associated with asbestos, the relationship between asbestos and PMM is lower. Kraynie et al. reported that malignant mesothelioma without association of asbestos occurred in young, female, peritoneal site diseases, with epithelioid histology [84]. In Butnor's report, while two cases of PMM had a history of paraoccupational exposure of asbestos, it was unknown whether their exposure to asbestos was enough to cause PMM [83]. They discussed the association between chronic inflammatory conditions in the peritoneum and malignant mesothelioma, such as interleukin- $1 \beta$ induction in endometriotic tissue by upregulation of intracellular estrogen receptor- $\beta$.

\subsection{Urinary Tract}

It is estimated that $1-3 \%$ of endometriosis occurs in the urinary tract and affects the bladder, ureter, and kidney in a ratio of 50:4:1 [85]. In this literature, cases occurring in the bladder were also the most common (10/17cases). In the bladder, the most common symptom was hematuria, which was a typical symptom of malignancy in the urinary tract. On the other hand, in the ureter cases, four cases complained of pain (three cases, ureteral obstruction) and only one case had symptoms of hematuria. Regarding the seven ureter cases, four cases with detailed description of endometriosis were suspected to be an extrinsic type. It is known that the extrinsic type occurs at a rate four times higher than the intrinsic type in endometriosis of the ureter [85], so pelvic pain or ureteral obstruction might occur earlier than hematuria. In addition, it has been reported that $70 \%$ of endometriosis is on the left side, because there are anatomical differences in the diffusion of retrograde menstrual blood being delayed by the sigmoid colon [85]. Four ureter cases were on the left side [20,85-87], compared to three cases on the right side, in this literature [20,88,89].

In this review, 10 of 17 cases $(58.8 \%)$ had a history of gynecological surgery which was thought to be a risk factor. Healy et al. reported that $60-70 \%$ of cases of urinary tract endometriosis had a history of pelvic surgery [85].

The most common histological type was CCC. However, the reason for this has not been clearly described in any published report. Clear cell carcinoma of the bladder is rare and accounts for $0.5-2 \%$ of epithelial malignancies at this site [90]. In the lower urinary tract, there are several hypotheses that CCC develops from Müllerian origin, mesonephric origin, or differentiation from urothelium [91]. However, these hypotheses are still controversial [91]. In the upper urinary tract, distinguishing it from the mesonephric clear cell renal cell carcinoma is required.

\subsection{Uterine Cervix}

Endometriosis of the cervix is estimated to occur in 3\% of cases [76]. Obstetrical or surgical trauma, such as biopsy, dilation and curettage (D\&C), or vaginal delivery, could be a cause of implantation of endometrial tissue [92]. On the other hand, Hashiguchi et al. reported a case of a nulliparous woman with a lesion in the deep cervix associated with adenomyosis and ovarian endometriosis [93]. Recently, Kishi et al. examined subtypes of adenomyosis and proposed the hypothesis of invasion of endometriotic tissues from outside the uterus [94]. Two other cases also had adenomyosis. Therefore, cervical endometriosis is thought to be almost the same disease of malignancy as adenomyosis $[95,96]$. The results of cervical cytology of CCC and EC were class V in one case [96] and class I in two cases [92,93] and a case of ESS has also been diagnosed with mild glandular atypia [95]. In addition to usual cervical adenocarcinoma, it may sometimes be difficult to diagnose malignancy using cytology.

\subsection{Others}

From one case in the lower chest wall and two cases in the diaphragm, Okimura et al. reviewed all three and indicated that all three cases had a history of intrapelvic surgery for endometriosis or adenomyosis [97-99]. They also described the possibility of a correlation 
between the severity of previous endometriosis and dissemination of endometriotic tissue by surgery [99]. The possibility of hematogenous spread could not be ruled out in a case of the right chest wall [97]. However, this is most likely to be caused by dissemination because the patient had a history of surgery for $3.5 \mathrm{~L}$ of bloody ascites, revealed endometriosis in omentum and serosa of appendix [97]. In both cases of inguinal onset and liver lesions, there was no coexistence of endometriotic tissue, and it was unclear whether they were truly derived from endometriosis $[30,100,101]$.

\subsection{Hormonal Therapy}

In a study of EAIT, Slavin et al. summarized a history of endometriosis, hysterectomy, adnexal resection, and hormonal therapy [22]. They described that many cases had welldifferentiated tumors and a history of long-term hormone replacement therapy, averaging 17 years [22]. Heaps et al. also described endometriosis-related ovarian malignancies and found that cases that were considered to be hypoestrogenism, such as HRT, estrogen acidic tumor, ovarian stromal hyperplasia, and endogenous androgenic conversion, tended to be well-differentiated tumors with a 5-year survival rate of $82 \%$ [18].

Regarding mesenchymal tumors, Masand et al. reported a series of 63 cases of endometrioid stromal sarcoma and that the majority of postmenopausal cases had undergone hormone replacement therapy for more than 10 years, suggesting an increased risk of progression of endometrioid stromal sarcoma [57]. Staats et al. described cases of endometriosis-associated malignancy in the vaginal stump, and 5 out of 16 endometriosisrelated malignant tumor cases had undergone hormone replacement therapy, resulting in no strong correlation [23]. In another hypothesis, peripheral conversion of androgen hormones into estrogens in the fat tissue may play the same role as estrogen therapy does, particularly in obese patients [79]. In this review, 119 patients were mentioned in relation to the presence or absence of hormone therapy. Estrogen monotherapy was administered in 33 cases (27.7\%), including OC and hormone replacement therapy in 46 cases (38.7\%). Many cases did not describe details of hormonal therapy. Therefore, we could not conclude risk occurrence.

Heaps et al. described that progestin supplementation could theoretically prevent growth of estrogen-dependent tumors [18]. However, eight cases in this study received progestin administration. Therefore, it may not be wise to ignore the occurrence of malignancy in some patients. In addition, Pokieser et al. reported a patient who was treated with MPA for 2 years and had a history of intra-abdominal hemorrhage due to rupture of ovarian endometriosis [102]. However, clear cell carcinoma from endometriosis arose in the rectum later [102]. They considered that the short duration of MPA administration may not have contributed to the prevention of malignant transformation [102].

Although many authors have suggested risks due to estrogen therapy, it is still controversial. However, considering the high differentiation and hormone-dependency characteristics of endometriosis-associated malignancy, physicians should be careful about estrogen monotherapy after hysterectomy and long-term hormone replacement therapy for patients with a history of endometriosis.

\subsection{Etiology and Histology}

Ectopic endometrial cells disseminated in the peritoneal cavity are conditioned to survive and proliferate by inflammatory cytokines and remodeling of the peritoneal microenvironment by MMPs, and reduced NK cell activity is also known to support the survival of endometriotic cells in the peritoneal cavity [103,104].

In addition to this unique microenvironment formed in endometriosis foci, it is also known that the hyperestrogenic state, which increases with worsening disease, contributes to reduced immune surveillance by enhancing Treg activity, in addition to promoting proliferation of endometriotic tissue [103].

In addition to these changes in the surrounding environment that can promote carcinogenesis, when cystic lesions occur in the ovaries, old blood in the cysts produces iron oxide 
in the cysts, which promotes carcinogenesis through genomic DNA mutations [105]. It has also been reported that endometriosis causes a disruption of redox metabolism, which may lead to the acquisition of cancer-specific metabolism in clear cell carcinoma [12].

Cancer genomic mutations have also been reported for extraovarian endometriosis in recent years, and mutations in cancer-associated genes, such as PIK3CA, KRAS, and ARID1A, have been identified [106]. In this review, the most common histological type with regard to extraovarian endometriosis was endometrial carcinoma, with CCC being the second most common. As mentioned by Mandai et al., a factor may be that most extraovarian endometriosis, such as deep endometriosis and intestinal endometriosis, rarely form large cysts, unlike in the ovary [20]. They did not include cases of malignant transformation of abdominal scars and epigiotomy scars, but in this review, 44 cases were described and CCC was frequently observed. Although it is difficult to clarify the cause of the appearance of histologic differences from intra-abdominal, deep endometriosis and intestinal endometriosis, the environment of the wound may affect the selection and metabolism of the implanted endometriotic cell.

In this study, many sarcoma cases were included, such as CS, EES, and AS, which accounted for $22 \%$ of the cases. Uterine CS is a homogeneous tumor and epithelialmesenchymal transition (EMT) has been proposed as a hypothesis, and a similar mechanism is assumed for CS derived from endometriosis [107]. On the other hand, there is no clear evidence that EES and AS are caused as a result of EMT, and it has not been clarified whether endometriotic stromal cells derive from normal endometrial stromal cells. It is difficult to estimate causality or epidemiological proportions from this study, and we hope that further investigations will be conducted.

\subsection{Limitations}

There are some limitations in this review. First, our review excludes non-English studies, so racial or regional differences were not considered. Second, the use of only the PubMed database and the manual search is another limitation to the study. Third, because of the rarity, our data did not include any large population-based studies. Thus, the data about prognosis or prevalence are limited.

\section{Conclusions}

Various sites and histological types of reports of extraovarian endometriosis have been established. Unlike ovarian endometriosis, the accurate incidence is uncertain because the prevalence has not been clarified. The proportion of histological types varied depending on the site of origin. This result indicated that differences in the microenvironment at the site influenced carcinogenesis. A comparison of these differences may clarify the mechanisms for malignant transformation of endometriosis. In the case of hormonal therapy for postmenopausal women, even if they have a history of bilateral oophorectomy, physicians should be careful about less/rare site endometriosis, especially estrogen monotherapy after hysterectomy.

Supplementary Materials: The following are available online at https:/ /www.mdpi.com/article/10 .3390/endocrines2030024/s1, Figure S1.

Author Contributions: Conceptualization and methodology, A.I.; collection of data, N.I and A.I.; validation, T.H., Y.K. and J.M.; investigation, N.I. and A.I.; data curation, N.I., A.I., T.H. and J.M.; writing—original draft preparation, N.I.; writing—review and editing, N.I., A.I., T.H., J.M. and Y.K.; supervision, A.I.; project administration, N.I. and A.I. All authors have read and agreed to the published version of the manuscript.

Funding: This research received no external funding.

Institutional Review Board Statement: Not applicable.

Informed Consent Statement: Not applicable. 
Data Availability Statement: The data that support the findings of this study are available from the corresponding author A.I. upon reasonable request.

Conflicts of Interest: The authors declare no conflict of interest.

\section{References}

1. Giudice, L.C. Clinical practice. Endometriosis. N. Engl. J. Med. 2010, 362, 2389-2398. [CrossRef]

2. Clement, P.B. Disease of the peritoneum. In Blaustein's Pathology of the Female Genital Tract, 6th ed.; Kurman, R.J., Hedrick Ellenson, L., Ronnett, B.M., Eds.; Springer: New York, NY, USA, 2011; pp. 625-678.

3. Haydardedeoglu, B.; Zeyneloglu, H.B. The impact of endometriosis on fertility. Womens Health 2015, 11, 619-623. [CrossRef] [PubMed]

4. Mounsey, A.L.; Wilgus, A.; Slawson, D.C. Diagnosis and management of endometriosis. Am. Fam. Physician 2006, 74, 594-600. [PubMed]

5. Sampson, J.A. Heterotopic or misplaced endometrial tissue. Amer. J. Obs. Gynecol. 1925, 10, 649-664. [CrossRef]

6. Scott, R.B. Malignant changes in endometriosis. Obs. Gynecol. 1953, 2, 283-289.

7. Benoit, L.; Arnould, L.; Cheynel, N.; Diane, B.; Causeret, S.; Machado, A.; Collin, F.; Fraisse, J.; Cuisenier, J. Malignant extraovarian endometriosis: A review. Eur. J. Surg. Oncol. 2006, 32, 6-11. [CrossRef]

8. Kobayashi, H.; Sumimoto, K.; Moniwa, N.; Imai, M.; Takakura, K.; Kuromaki, T.; Morioka, E.; Arisawa, K.; Terao, T. Risk of developing ovarian cancer among women with ovarian endometrioma: A cohort study in Shizuoka, Japan. Int. J. Gynecol. Cancer 2007, 17, 37-43. [CrossRef]

9. Pearce, C.L.; Templeman, C.; Rossing, M.A.; Lee, A.; Near, A.M.; Webb, P.M.; Nagle, C.M.; Doherty, J.A.; Cushing-Haugen, K.L.; Wicklund, K.G.; et al. Association between endometriosis and risk of histological subtypes of ovarian cancer: A pooled analysis of case-control studies. Lancet Oncol. 2012, 13, 385-394. [CrossRef]

10. Wentzensen, N.; Poole, E.M.; Trabert, B.; White, E.; Arslan, A.A.; Patel, A.V.; Setiawan, V.W.; Visvanathan, K.; Weiderpass, E.; Adami, H.O.; et al. Ovarian cancer risk factors by histologic subtype: An analysis from the ovarian cancer cohort consortium. J. Clin. Oncol. 2016, 34, 2888-2898. [CrossRef]

11. Taniguchi, F.; Harada, T.; Kobayashi, H.; Hayashi, K.; Momoeda, M.; Terakawa, N. Clinical characteristics of patients in Japan with ovarian cancer presumably arising from ovarian endometrioma. Gynecol. Obs. Invest. 2014, 77, 104-110. [CrossRef]

12. Králíčková, M.; Vetvicka, V. Endometriosis and ovarian cancer. World J. Clin. Oncol. 2014, 5, 800-805. [CrossRef]

13. Fukunaga, M.; Nomura, K.; Ishikawa, E.; Ushigome, S. Ovarian atypical endometriosis: Its close association with malignant epithelial tumours. Histopathology 1997, 30, 249-255. [CrossRef]

14. Ogawa, S.; Kaku, T.; Amada, S.; Kobayashi, H.; Hirakawa, T.; Ariyoshi, K.; Kamura, T.; Nakano, H. Ovarian endometriosis associated with ovarian carcinoma: A clinicopathological and immunohistochemical study. Gynecol. Oncol. 2000, 77, 298-304. [CrossRef] [PubMed]

15. Sato, N.; Tsunoda, H.; Nishida, M.; Morishita, Y.; Takimoto, Y.; Kubo, T.; Noguchi, M. Loss of heterozygosity on $10 q 23.3$ and mutation of the tumor suppressor gene PTEN in benign endometrial cyst of the ovary: Possible sequence progression from benign endometrial cyst to endometrioid carcinoma and clear cell carcinoma of the ovary. Cancer Res. 2000, 60, 7052-7056.

16. Wiegand, K.C.; Shah, S.P.; Al-Agha, O.M.; Zhao, Y.; Tse, K.; Zeng, T.; Senz, J.; McConechy, M.K.; Anglesio, M.S.; Kalloger, S.E.; et al. ARID1A mutations in endometriosis-associated ovarian carcinomas. N. Engl. J. Med. 2010, 363, 1532-1543. [CrossRef] [PubMed]

17. Yamamoto, S.; Tsuda, H.; Takano, M.; Iwaya, K.; Tamai, S.; Matsubara, O. PIK3CA mutation is an early event in the development of endometriosis-associated ovarian clear cell adenocarcinoma. J. Pathol. 2011, 225, 189-194. [CrossRef]

18. Heaps, J.M.; Nieberg, R.K.; Berek, J.S. Malignant neoplasms arising in endometriosis. Obs. Gynecol. 1990, 75, 1023-1028. [CrossRef]

19. Irvin, W.; Pelkey, T.; Rice, L.; Andersen, W. Endometrial stromal sarcoma of the vulva arising in extraovarian endometriosis: A case report and literature review. Gynecol. Oncol. 1998, 71, 313-316. [CrossRef]

20. Mandai, M.; Osuga, Y.; Hirata, T.; Enomoto, T.; Nakai, H.; Honda, R.; Taniguchi, F.; Katabuchi, H. Cancers associated with extraovarian endometriosis at less common/rare sites: A nationwide survey in Japan. J. Obs. Gynaecol. Res. 2020, 46, 917-923. [CrossRef]

21. Fishman, A.; Demirel, D.; Laucirica, R.; Ramzy, I.; Klima, T.; Lyzak, J.; Kaplan, A.L. Malignant tumors arising in endometriosis: Clinical-pathological study and flow cytometry analysis. Eur. J. Obs. Gynecol. Reprod. Biol. 1996, 70, 69-74. [CrossRef]

22. Slavin, R.E.; Krum, R.; Van Dinh, T. Endometriosis-associated intestinal tumors: A clinical and pathological study of 6 cases with a review of the literature. Hum. Pathol. 2000, 31, 456-463. [CrossRef]

23. Staats, P.N.; Clement, P.B.; Young, R.H. Primary endometrioid adenocarcinoma of the vagina: A clinicopathologic study of 18 cases. Am. J. Surg. Pathol. 2007, 31, 1490-1501. [CrossRef]

24. Herawi, M.; Drew, P.A.; Pan, C.C.; Epstein, J.I. Clear cell adenocarcinoma of the bladder and urethra: Cases diffusely mimicking nephrogenic adenoma. Hum. Pathol. 2010, 41, 594-601. [CrossRef]

25. Nezhat, F.R.; DeNoble, S.M.; Brown, D.N.; Shamshirsaz, A.; Hoehn, D. Laparoscopic management of peritoneal mesothelioma associated with pelvic endometriosis. J. Minim. Invasive Gynecol. 2010, 17, 646-650. [CrossRef] [PubMed]

26. Groisman, G.M.; Kerner, H. Multicystic mesothelioma with endometriosis. Acta Obs. Gynecol. Scand. 1992, 71, 642-644. [CrossRef]

27. Kurisu, Y.; Tsuji, M.; Shibayama, Y.; Yamada, T.; Ohmichi, M. Multicystic mesothelioma caused by endometriosis: 2 case reports and review of the literature. Int. J. Gynecol. Pathol. 2011, 30, 163-166. [CrossRef] [PubMed] 
28. Mangal, R.; Taskin, O.; Franklin, R. An incidental diagnosis of well-differentiated papillary mesothelioma in a woman operated on for recurrent endometriosis. Fertil. Steril. 1995, 63, 196-197. [CrossRef]

29. Zotalis, G.; Nayar, R.; Hicks, D.G. Leiomyomatosis peritonealis disseminata, endometriosis, and multicystic mesothelioma: An unusual association. Int. J. Gynecol. Pathol. 1998, 17, 178-182. [CrossRef]

30. Khan, A.W.; Craig, M.; Jarmulowicz, M.; Davidson, B.R. Liver tumours due to endometriosis and endometrial stromal sarcoma. HPB 2002, 4, 43-45. [CrossRef]

31. Chu, I.L.; Chen, C.L.; Hsu, C.S. Adenofibroma of the uterine cervix coexistent with endometriosis. Taiwan J. Obs. Gynecol. 2012, 51, 285-288. [CrossRef] [PubMed]

32. Banz, C.; von Otte, S.; Noack, F.; Diedrich, K.; Hornung, D. Primary peritoneal carcinoma in a young woman with suspected endometriosis. Fertil. Steril. 2009, 92, e5-e7. [CrossRef]

33. Alessandrini, L.; Sopracordevole, F.; Bertola, G.; Scalone, S.; Urbani, M.; Miolo, G.; Perin, T.; Italia, F.; Canzonieri, V. Primary extragenital endometrial stromal sarcoma of the lung: First reported case and review of literature. Diagn. Pathol. 2017, 12, 36. [CrossRef]

34. Aust, S.; Tiringer, D.; Grimm, C.; Stani, J.; Langer, M. Therapy of a clear cell adenocarcinoma of unknown primary arising in the abdominal wall after cesarean section and after hysterectomy. Wien. Klin. Wochenschr. 2015, 127, 62-64. [CrossRef] [PubMed]

35. Harimoto, N.; Hagiwara, K.; Yamanaka, T.; Ishii, N.; Igarashi, T.; Watanabe, A.; Kubo, N.; Araki, K.; Ikota, H.; Suyama, M.; et al. Fairly rare clear cell adenocarcinoma mimicking liver cancer: A case report. Surg. Case Rep. 2018, 4, 97. [CrossRef] [PubMed]

36. Insabato, L.; Natella, V.; Somma, A.; Persico, M.; Camera, L.; Losito, N.S.; Masone, S. Primary peritoneal clear cell carcinoma versus ovarian carcinoma versus malignant transformation of endometriosis: A vexing issue. Int. J. Surg. Pathol. 2015, 23, 211-216. [CrossRef]

37. Kojima, N.; Yoshida, H.; Uehara, T.; Ushigusa, T.; Asami, Y.; Shiraishi, K.; Kato, T. Primary clear cell adenocarcinoma of the vulva: A case study with mutation analysis and literature review. Int. J. Surg. Pathol. 2019, 27, 792-797. [CrossRef] [PubMed]

38. Lim, K.C.; Thompson, I.W.; Wiener, J.J. A case of primary clear cell adenocarcinoma of Bartholin's gland. BJOG 2002, 109, 1305-1307. [CrossRef]

39. Makihara, N.; Fujita, I.; Soudaf, H.; Yamamoto, T.; Sashikata, T.; Mukohara, T.; Maeda, T. A case of endometrioid adenocarcinoma originating from the serous surface of the small intestine. Rare Tumors 2015, 7, 5932. [CrossRef] [PubMed]

40. Higuchi, M.; Yamaura, T.; Kanno, R.; Suzuki, H.; Asano, S.; Gotoh, M. Incidental early lung adenocarcinoma after surgery for catamenial pneumothorax. Fukushima J. Med. Sci. 2012, 58, 74-77. [CrossRef] [PubMed]

41. Kholová, I.; Ryska, A.; Dedic, K. Composite tumor consisting of dermatofibrosarcoma protuberans and giant cell fibroblastoma associated with intratumoral endometriosis. Report of a case. Pathol. Res. Pr. 2001, 197, 263-267; discussion 269-270. [CrossRef] [PubMed]

42. Yang, Q.; Wang, H.; Cho, H.Y.; Jung, S.J.; Kim, K.R.; Ro, J.Y.; Shen, S.S. Carcinoma of müllerian origin presenting as colorectal cancer: A clinicopathologic study of 13 cases. Ann. Diagn. Pathol. 2011, 15, 12-18. [CrossRef] [PubMed]

43. Falleni, M.; Bauer, D.; Opocher, E.; Moneghini, L.; Bulfamante, G.P. A rare case of transmural endometriosis in primary adenocarcinoma of the rectum. Pathologica 2014, 106, 14-15.

44. Klingbeil, K.D.; Azab, B.; Moller, M.G. Low-grade appendiceal mucinous neoplasm and endometriosis of the appendix. World J. Surg. Oncol. 2017, 15, 226. [CrossRef] [PubMed]

45. Alkady, H.; Abouramadan, S.; Nagy, M.; Talaat, A.; Hashem, T.; Khaleel, A. Removal of an endometrioid stromal sarcoma from the inferior vena cava and right atrium. Gen. Thorac. Cardiovasc. Surg. 2019, 67, 324-327. [CrossRef]

46. Baiocchi, G.; Kavanagh, J.J.; Wharton, J.T. Endometrioid stromal sarcomas arising from ovarian and extraovarian endometriosis: Report of two cases and review of the literature. Gynecol. Oncol. 1990, 36, 147-151. [CrossRef]

47. Kondi-Paphitis, A.; Smyrniotis, B.; Liapis, A.; Kontoyanni, A.; Deligeorgi, H. Stromal sarcoma arising on endometriosis. A clinicopathological and immunohistochemical study of 4 cases. Eur. J. Gynaecol. Oncol. 1998, 19, 588-590. [PubMed]

48. Tinelli, A.; Malvasi, A.; Pellegrino, M. An incidental peritoneal serous borderline tumor during laparoscopy for endometriosis. Eur. J. Gynaecol. Oncol. 2009, 30, 579-582. [PubMed]

49. Alcázar, J.L.; Guerriero, S.; Ajossa, S.; Parodo, G.; Piras, B.; Peiretti, M.; Jurado, M.; Idoate, M. Extragenital endometrial stromal sarcoma arising in endometriosis. Gynecol. Obs. Invest. 2012, 73, 265-271. [CrossRef]

50. Macafee, C.H.; Greer, H.L. Intestinal endometriosis. A report of 29 cases and a survey of the literature. J. Obs. Gynaecol. Br. Emp. 1960, 67, 539-555. [CrossRef]

51. Evans, H.; Yates, W.A.; Palmer, W.E.; Cartwright, R.L.; Antemann, R.W. Clear cell carcinoma of the sigmoid mesocolon: A tumor of the secondary müllerian system. Am. J. Obs. Gynecol. 1990, 162, 161-163. [CrossRef]

52. Ardila-Gatas, J.; Durand, P.; Patil, D.T.; Gorgun, E. Unusual presentation of endometrioid adenocarcinoma arising in colonic endometriosis. A case report. Int. J. Colorectal Dis. 2016, 31, 733-734. [CrossRef] [PubMed]

53. Molberg, K.; Ashfaq, R.; Gokaslan, S.T.; Shires, T. Endometrioid carcinoma arising in pericecal endometriosis clinically mimicking Crohn's disease. Ann. Diagn. Pathol. 2000, 4, 29-33. [CrossRef]

54. Ayuso, A.; Fadare, O.; Khabele, D. A case of extrauterine endometrial stromal sarcoma in the colon diagnosed three decades after hysterectomy for benign disease. Case Rep. Obs. Gynecol. 2013, 2013, 202458. [CrossRef]

55. Caballero, Y.; Turégano, A.; López-Tomassetti, E.; Martínez, M.S.; Benito, V.; Hernández, J.R. Endometrioid adenocarcinoma in the lower rectum. Rev. Esp. Enferm. Dig. 2013, 105, 567-569. [CrossRef] [PubMed] 
56. Chu, P.; Wu, E.; Weiss, L.M. Cytokeratin 7 and cytokeratin 20 expression in epithelial neoplasms: A survey of 435 cases. Mod. Pathol. 2000, 13, 962-972. [CrossRef] [PubMed]

57. Masand, R.P.; Euscher, E.D.; Deavers, M.T.; Malpica, A. Endometrioid stromal sarcoma: A clinicopathologic study of 63 cases. Am. J. Surg. Pathol. 2013, 37, 1635-1647. [CrossRef]

58. Chen, C.W.; Ou, J.J.; Wu, C.C.; Hsiao, C.W.; Cheng, M.F.; Jao, S.W. High-grade endometrial stromal sarcoma arising from colon endometriosis. Int. J. Colorectal Dis. 2007, 22, 1551-1553. [CrossRef]

59. Cho, H.Y.; Kim, M.K.; Cho, S.J.; Bae, J.W.; Kim, I. Endometrial stromal sarcoma of the sigmoid colon arising in endometriosis: A case report with a review of literatures. J. Korean Med. Sci. 2002, 17, 412-414. [CrossRef]

60. Wang, Q.; Zhao, X.; Han, P. Endometrial stromal sarcoma arising in colorectal endometriosis: A case report and review of the literature. Case Rep. Obs. Gynecol. 2015, 2015, 534273. [CrossRef] [PubMed]

61. Han, A.C.; Hovenden, S.; Rosenblum, N.G.; Salazar, H. Adenocarcinoma arising in extragonadal endometriosis: An immunohistochemical study. Cancer 1998, 83, 1163-1169. [CrossRef]

62. Tsuruga, T.; Hirata, T.; Akiyama, I.; Matsumoto, Y.; Oda, K.; Fujii, T.; Osuga, Y. Mixed endometrioid and clear cell carcinoma arising from laparoscopic trocar site endometriosis. J. Obs. Gynaecol. Res. 2019, 45, 1613-1618. [CrossRef]

63. Matsuo, K.; Alonsozana, E.L.; Eno, M.L.; Rosenshein, N.B.; Im, D.D. Primary peritoneal clear cell adenocarcinoma arising in previous abdominal scar for endometriosis surgery. Arch. Gynecol. Obs. 2009, 280, 637-641. [CrossRef]

64. Achach, T.; Rammeh, S.; Trabelsi, A.; Ltaief, R.; Ben Abdelkrim, S.; Mokni, M.; Korbi, S. Clear cell adenocarcinoma arising from abdominal wall endometriosis. J. Oncol. 2008, 2008, 478325. [CrossRef] [PubMed]

65. Omranipour, R.; Najafi, M. Papillary serous carcinoma arising in abdominal wall endometriosis treated with neoadjuvant chemotherapy and surgery. Fertil. Steril. 2010, 93, e17-e18. [CrossRef]

66. Fargas Fàbregas, F.; Cusidó Guimferrer, M.; Tresserra Casas, F.; Baulies Caballero, S.; Fábregas Xauradó, R. Malignant transformation of abdominal wall endometriosis with lymph node metastasis: Case report and review of literature. Gynecol. Oncol. Case Rep. 2014, 8, 10-13. [CrossRef] [PubMed]

67. Drukała, Z.; Ciborowska-Zielińska, B.; Kubrak, J.; Rogowska, D. Outcome of a multimodal therapy of a recurrent adenocarcinoma arising from Caesarean section scar endometriosis-A case report. Rep. Pr. Oncol. Radiother. 2010, 15, 75-77. [CrossRef] [PubMed]

68. Bats, A.S.; Zafrani, Y.; Pautier, P.; Duvillard, P.; Morice, P. Malignant transformation of abdominal wall endometriosis to clear cell carcinoma: Case report and review of the literature. Fertil. Steril. 2008, 90, e13-e16. [CrossRef]

69. Shalin, S.C.; Haws, A.L.; Carter, D.G.; Zarrin-Khameh, N. Clear cell adenocarcinoma arising from endometriosis in abdominal wall cesarean section scar: A case report and review of the literature. J. Cutan. Pathol. 2012, 39, 1035-1041. [CrossRef]

70. Ferrandina, G.; Palluzzi, E.; Fanfani, F.; Gentileschi, S.; Valentini, A.L.; Mattoli, M.V.; Pennacchia, I.; Scambia, G.; Zannoni, G. Endometriosis-associated clear cell carcinoma arising in caesarean section scar: A case report and review of the literature. World J. Surg. Oncol. 2016, 14, 300. [CrossRef]

71. Leng, J.; Lang, J.; Guo, L.; Li, H.; Liu, Z. Carcinosarcoma arising from atypical endometriosis in a cesarean section scar. Int. J. Gynecol. Cancer 2006, 16, 432-435. [CrossRef]

72. Li, J.Y.; Chen, Y.J.; Wu, Y.C.; Hung, J.H.; Yuan, C.C.; Shu, L.P.; Wang, P.H. Two- and three-dimensional Doppler ultrasound analysis of abdominal wall clear cell carcinoma. Ultrasound Obs. Gynecol. 2003, 22, 98-100. [CrossRef]

73. Mert, I.; Semaan, A.; Kim, S.; Ali-Fehmi, R.; Morris, R.T. Clear cell carcinoma arising in the abdominal wall: Two case reports and literature review. Am. J. Obs. Gynecol. 2012, 207, e7-e9. [CrossRef] [PubMed]

74. Stevens, E.E.; Pradhan, T.S.; Chak, Y.; Lee, Y.C. Malignant transformation of endometriosis in a cesarean section abdominal wall scar: A case report. J. Reprod. Med. 2013, 58, 264-266. [PubMed]

75. Tajima, S.; Bito, T.; Ikeda, T.; Mukohara, T.; Nishigori, C. Cutaneous endometrial cancer arising from heterotopic endometriosis in an abdominal caesarean section scar. J. Eur. Acad. Derm. Venereol. 2016, 30, 683-685. [CrossRef]

76. Stern, R.C.; Dash, R.; Bentley, R.C.; Snyder, M.J.; Haney, A.F.; Robboy, S.J. Malignancy in endometriosis: Frequency and comparison of ovarian and extraovarian types. Int. J. Gynecol. Pathol. 2001, 20, 133-139. [CrossRef] [PubMed]

77. Shah, C.; Pizer, E.; Veljovich, D.S.; Drescher, C.W.; Peters, W.A.; Paley, P.J. Clear cell adenocarcinoma of the vagina in a patient with vaginal endometriosis. Gynecol. Oncol. 2006, 103, 1130-1132. [CrossRef]

78. Buppasiri, P.; Kleebkaow, P.; Tharanon, C.; Aue-Aungkul, A.; Kietpeerakool, C. Clear cell carcinoma arising in vulvar endometriosis. Case Rep. Pathol. 2018, 2018, 4263104. [CrossRef]

79. Andriola, V.; Battaglia, M.; Ditonno, P.; Fiore, M.G.; De Fazio, M.; Memeo, R.; Altomare, D.F. The unexpected conundrum of endometrioid carcinoma in deep rectal endometriosis arising 11 years after total hysterectomy bilateral salpingo-oophorectomy. Int. J. Colorectal Dis. 2016, 31, 475-477. [CrossRef]

80. Shigeta, N.; Yoshino, K.; Matsuzaki, S.; Morii, E.; Ueda, Y.; Kimura, T. Clear cell adenocarcinoma of the peritoneum: A case report and literature review. J. Ovarian Res. 2014, 7, 86. [CrossRef]

81. Johnson, S.B.; Prisciandaro, J.I.; Zhou, J.; Hadley, S.W.; Reynolds, R.K.; Jolly, S. Primary peritoneal clear cell carcinoma treated with IMRT and interstitial HDR brachytherapy: A case report. J. Appl. Clin. Med. Phys. 2014, 15, 4520. [CrossRef]

82. Kusaka, M.; Mikuni, M.; Nishiya, M. A case of high-grade endometrial stromal sarcoma arising from endometriosis in the cul-de-sac. Int. J. Gynecol. Cancer 2006, 16, 895-899. [CrossRef]

83. Butnor, K.J.; Rueckert, J.; Pavlisko, E.N.; Sporn, T.A.; Roggli, V.L. Malignant peritoneal mesothelioma in patients with endometriosis. J. Clin. Pathol. 2018, 71, 971-974. [CrossRef] [PubMed] 
84. Kraynie, A.; de Ridder, G.G.; Sporn, T.A.; Pavlisko, E.N.; Roggli, V.L. Malignant mesothelioma not related to asbestos exposure: Analytical scanning electron microscopic analysis of 83 cases and comparison with 442 asbestos-related cases. Ultrastruct. Pathol. 2016, 40, 142-146. [CrossRef]

85. Healy, K.A.; Carney, K.J.; Osunkoya, A.O. Endometrioid adenocarcinoma in the native ureter of a renal transplant patient: Case report and review of the literature. Sci. World J. 2010, 10, 1714-1722. [CrossRef] [PubMed]

86. Osaku, D.; Taniguchi, F.; Moriyama, M.; Sato, S.; Oishi, T.; Harada, T. Retroperitoneal endometrioid carcinoma arising from ureteral endometriosis. Case Rep. Obs. Gynecol. 2019, 2019, 9273858. [CrossRef]

87. Vierhout, M.E.; Chadha-Ajwani, S.; Wijnen, J.A.; Splinter, T.A.; Zondervan, P.E.; Ras, J.H.; Drogendijk, A.C. Extra-uterine endometrial stromal sarcoma with DNA flow cytometric analysis. Eur. J. Obs. Gynecol. Reprod. Biol. 1992, 43, 157-161. [CrossRef]

88. Salerno, M.G.; Masciullo, V.; Naldini, A.; Zannoni, G.F.; Vellone, V.; Scambia, G. Endometrioid adenocarcinoma with squamous differentiation arising from ureteral endometriosis in a patient with no history of gonadal endometriosis. Gynecol. Oncol. 2005, 99, 749-752. [CrossRef] [PubMed]

89. Jimenez, R.E.; Tiguert, R.; Hurley, P.; An, T.; Grignon, D.J.; Lawrence, D.; Triest, J. Unilateral hydronephrosis resulting from intraluminal obstruction of the ureter by adenosquamous endometrioid carcinoma arising from disseminated endometriosis. Urology 2000, 56, 331. [CrossRef]

90. Balat, O.; Kudelka, A.P.; Edwards, C.L.; Silva, E.; Kavanagh, J.J. Malignant transformation in endometriosis of the urinary bladder: Case report of clear cell adenocarcinoma. Eur. J. Gynaecol. Oncol. 1996, 17, 13-16.

91. Miller, E.M.; Sun, Y.; Richardson, I.; Frimer, M. Vesical clear cell adenocarcinoma arising from endometriosis: A mullerian tumor, indistinguishable from ovarian clear cell adenocarcinoma. Gynecol. Oncol. Rep. 2016, 18, 8-10. [CrossRef]

92. Hiromura, T.; Tanaka, Y.O.; Nishioka, T.; Satoh, M.; Tomita, K. Clear cell adenocarcinoma of the uterine cervix arising from a background of cervical endometriosis. Br. J. Radiol. 2009, 82, e20-e22. [CrossRef]

93. Hashiguchi, M.; Kai, K.; Nishiyama, S.; Nakao, Y.; Yokoyama, M.; Aishima, S. Clear cell carcinoma of the uterine cervix presented as a submucosal tumor arising in a background of cervical endometriosis. Int. J. Gynecol. Pathol. 2018, 37, 88-92. [CrossRef]

94. Kishi, Y.; Suginami, H.; Kuramori, R.; Yabuta, M.; Suginami, R.; Taniguchi, F. Four subtypes of adenomyosis assessed by magnetic resonance imaging and their specification. Am. J. Obs. Gynecol. 2012, 207, e1-e7. [CrossRef]

95. Hasiakos, D.; Papakonstantinou, K.; Kondi-Paphiti, A.; Fotiou, S. Low-grade endometrial stromal sarcoma of the endocervix. Report of a case and review of the literature. Eur. J. Gynaecol. Oncol. 2007, 28, 483-486.

96. Park, H.M.; Lee, S.S.; Eom, D.W.; Kang, G.H.; Yi, S.W.; Sohn, W.S. Endometrioid adenocarcinoma arising from endometriosis of the uterine cervix: A case report. J. Korean Med. Sci. 2009, 24, 767-771. [CrossRef] [PubMed]

97. Agrawal, A.; Nation, J.; Ghatage, P.; Chu, P.; Ross, S.; Magliocco, A. Malignant chest wall endometriosis: A case report and literature review. J. Obs. Gynaecol. Can. 2009, 31, 538-541. [CrossRef]

98. Fujiu, K.; Miyamoto, H.; Hashimoto, S.; Suzuki, N.; Takano, Y.; Teranishi, Y.; Sakuma, H.; Suzuki, H. A case of diaphragmatic clear cell carcinoma in a patient with a medical history of ovarian endometriosis. Int. J. Clin. Oncol. 2010, 15, 489-492. [CrossRef]

99. Okimura, H.; Tatsumi, H.; Ito, F.; Yamashita, S.; Kokabu, T.; Kitawaki, J. Endometrioid carcinoma arising from diaphragmatic endometriosis treated with laparoscopy: A case report. J. Obs. Gynaecol. Res. 2018, 44, 972-977. [CrossRef]

100. Ahn, G.H.; Scully, R.E. Clear cell carcinoma of the inguinal region arising from endometriosis. Cancer 1991, 67, 116-120. [CrossRef]

101. Hama, Y.; Iwasaki, Y.; Sakata, I.; Kusano, S. Primary peritoneal clear cell carcinoma. J. Comput. Assist. Tomogr. 2004, 28, 617-619. [CrossRef]

102. Pokieser, W.; Schmerker, R.; Kisser, M.; Peters-Engl, C.; Mühlbauer, H.; Ulrich, W. Clear cell carcinoma arising in endometriosis of the rectum following progestin therapy. Pathol. Res. Pr. 2002, 198, 121-124. [CrossRef]

103. Laganà, A.S.; Triolo, O.; Salmeri, F.M.; Granese, R.; Palmara, V.I.; Ban Frangež, H.; Vrtčnik Bokal, E.; Sofo, V. Natural Killer T cell subsets in eutopic and ectopic endometrium: A fresh look to a busy corner. Arch. Gynecol. Obs. 2016, 293, 941-949. [CrossRef]

104. Laganà, A.S.; Sturlese, E.; Retto, G.; Sofo, V.; Triolo, O. Interplay between misplaced müllerian-derived stem cells and peritoneal immune dysregulation in the pathogenesis of endometriosis. Obs. Gynecol. Int. 2013, 2013, 527041. [CrossRef]

105. Yamaguchi, K.; Mandai, M.; Toyokuni, S.; Hamanishi, J.; Higuchi, T.; Takakura, K.; Fujii, S. Contents of endometriotic cysts, especially the high concentration of free iron, are a possible cause of carcinogenesis in the cysts through the iron-induced persistent oxidative stress. Clin. Cancer Res. 2008, 14, 32-40. [CrossRef]

106. Anglesio, M.S.; Papadopoulos, N.; Ayhan, A.; Nazeran, T.M.; Noë, M.; Horlings, H.M.; Lum, A.; Jones, S.; Senz, J.; Seckin, T.; et al. Cancer-associated mutations in endometriosis without cancer. N. Engl. J. Med. 2017, 376, 1835-1848. [CrossRef]

107. Wada, H.; Enomoto, T.; Fujita, M.; Yoshino, K.; Nakashima, R.; Kurachi, H.; Haba, T.; Wakasa, K.; Shroyer, K.R.; Tsujimoto, M.; et al. Molecular evidence that most but not all carcinosarcomas of the uterus are combination tumors. Cancer Res. 1997, 57, $5379-5385$. 